\title{
STUDENT SUBJECTS: HUMAN LAB RATS OR GENUINE CONSUMERS?
}

Lauren M. Brewer, Louisiana Tech University

\begin{abstract}
For generations college students have participated in university studies for meager incentives such as a few points of extra credit, nominal cash amounts, or some other slight token of the researcher's appreciation. In marketing research, students evaluate often products for which they are unfamiliar, project themselves into pre-specified situations, and are asked to make pretend decisions regarding purchasing behaviors for things they have never and may never consider buying in their lifetime. Despite the criticism of college students as sample subjects, they may be useful "human lab rats" playing an important role in the development of marketing and/or consumer research.

Empirical studies in the Journal of Consumer Research (JCR) from 2000, 2005, and 2010 were examined for instances of student subjects evaluating a product or product category. $J C R$ was selected for analysis due to the abundance of empirical studies and student samples. The criteria for selection required that student-subjects evaluated at least one product independently, or as part of a larger consumption scenario and used at least one sample of students, either undergraduate or graduate level. A total of eighty one articles out of a possible one hundred seventy six fit these criteria and were selected for inclusion. In the session, patterns of usage are discussed.

Further, an exploratory empirical investigation was conducted using current college students (both undergraduate and graduate levels) and non-college students. The purpose of the study was to investigate whether different levels of knowledge existed between students and non-students for selected products or product categories that were used in published JCR journal articles from 2000 and 2010. Results from this exploratory research also are offered to generate discussion.

The results suggest that in general, differences in products and product category knowledge exist between student and nonstudent populations. As a result, the generalizability of results or the ability of the students to be ubiquitous representatives of the relevant consumer population may be suspect. The current study was simple in nature, looking only to see whether significant differences existed between groups at the level of overall product knowledge on a subjective basis. Further analysis will benefit from a shorter version of the scale used with additional analysis of objective measures.
\end{abstract}

